\section{LA SUPREMACIA \\ DE LOS PCGA (PRINCIPIOS DE CONTABILIDAD GENERALMENTE ACEPTADOS).}

\section{Dr. PASCUAL CHÁVEZ ACKERMANN.}

Los estados de cuentas financieros, los estándares de reportes financieros y reglamentos se basan en los Principios de Contabilidad Generalmente Aceptados (PCGA), los cuales describen los métodos para medir la ganancia y valorar activos y pasivos, así como conocer qué información debería ser descubierta en estados de cuentas financieros. Si usted lee los estados de cuentas financieros de una empresa; usted está autorizado a asumir que la empresa ha usado los PCGA al proveer adecuado descubrimiento de sus flujos de caja y ganancia y también su condición financiera al final de un período financiero.

Si los estados de cuentas financieros violan los PCGA y usted sufre una pérdida debido a que usted tomó la información financiera al pie de la letra, o sea en valor nominal (usted hizo decisiones basadas en la información contable de los estados de cuenta), usted posiblemente tenga base para enjuiciar a la empresa por daños. Por esta razón y no por otra, los gerentes de empresas deberían estar al tanto de los PCGA y deberían de asegurarse de que sus contadores aplican los PCGA en la preparación de los estados de cuentas financieros de la empresa.
Un ejemplo práctico de los PCGA : ¿ Por qué los Reglamentos son importantes?.

Los gerentes de empresas deberían conocer los rasgos principales de los PCGA aunque, en verdad, no todos los detalles técnicos, de tal manera que ellos entiendan cómo se mide la ganancia. A los gerentes se les paga para que produzcan ganancia, y ellos deberían ser muy transparentes en lo que se refiere a cómo se mide y en qué consiste la ganancia. Lo que estoy diciendo aquí es básicamente que la ganancia depende de cómo es definida y medida.

Por ejemplo, una empresa compra y mantiene productos para la venta; la acumulación de estos productos se llama "inventario". Una empresa registra la compra de productos al costo, que es la suma que pagó por los productos. El inventario es la acumulación de productos que se mantiene para vender a los clientes. Ejemplos incluyen ropas en un supermercado, combustible en los tanques de una estación de gasolina; alimentos en los anaqueles de un supermercado, libros en una librería, y así por consiguiente. El costo de los productos es colocado en la cuenta de activos del inventario y mantenido allí hasta que los productos son vendidos a los clientes. Cuando los productos son eventualmente vendidos, el costo de los productos son registrados como costo de mercaderías vendidas, a cuyo respectivo tiempo se registra un decrecimiento en la cuenta de activos del inventario. El costo de los productos vendidos es deducido de los réditos de ventas recibido de los clientes, lo cual da un primer paso de la medida de ganancia.

Ahora, suponga que antes de que la empresa venda los productos a sus clientes, el costo de reemplazo de muchos 
de los productos mantenidos en inventario, esperando ser vendidos, aumenta. El valor del costo de reemplazo de los productos, es ahora más alto que el original y real costo de compra de los productos. El inventario de la compañía vale más, ¿ no es así?, quizás la empresa podría aumentar los precios de venta que carga a sus clientes debido al incremento de costo, o quizás no. En cualquiera de los casos, ¿ debería el incremento de costo de reemplazo de los productos ser registrado como ganancia?. El gerente puede pensar que este beneficio retenido debería ser registrado como ganancia. Pero los estándares de la contabilidad (PCGA) dicen que ninguna ganancia es obtenida hasta que los productos son vendidos a los clientes.

¿ Qué le parece el movimiento opuesto en costos de reemplazo de productos, cuando los costos de reemplazo caen por debajo de los costos de compra originales?. ¿ Debería este desarrollo registrarse como una pérdida, o debería la empresa esperar hasta que el producto sea vendido?. Como usted verá, la regla de contabilidad que se aplica aquí es la llamada "baja de costo o mercado", y la pérdida es registrada. De tal manera que la regla requiere un método en la parte superior y otro método en la parte inferior. ¿ Se da cuenta de por qué los gerentes de empresas y los inversionistas necesitan saber algo de las reglas del juego?.

Una frecuente y repetida anécdota de contabilidad referente a una entrevista para un puesto importante de contador en una empresa, dice que, al candidato $\mathrm{N}^{\circ} 1$ se le hace la siguiente pregunta clave: ¿Cuánto es $2+2$ ?; él contesta 4, y le dicen "No nos llame, nosotros lo llamaremos". El candidato $\mathrm{N}^{\circ} 2$ contesta "Bueno, la mayoría de las veces la respuesta es 4 , pero algunas veces es 3 y en otras es $5^{\prime \prime}$.
El candidato $\mathrm{N}^{\circ} 3$ muy astutamente contesta" " ¿Cuál quiere usted que sea la respuesta?". Adivine: ¿Quién ganó el puesto?.

El caso es que los PCGA no son completamente herméticos o preparados de antemano. Muchos modelos de contabilidad dejan bastante lugar para la interpretación. La denominación de "Guías" sería una mejor forma de describir algunas reglas de contabilidad. Decidir cómo contabilizar ciertas transacciones y situaciones, requiere flexibilidad, juzgamiento oportuno, e interpretación cuidadosa de las reglas.

Algunas veces los contadores usan lo que se llama "contabilidad creativa" para que las ganancias del período financiero se vean mejor; como los abogados, quienes saben dónde encontrar escapatorias, los contadores algunas veces salen con soluciones "imaginativas", pero aún permanecen dentro de las guías de los PCGA. Yo les prevengo acerca de estas técnicas de contabilidad creativa, también llamadas "maquillando los números".

\section{El Impuesto a la Renta y las Reglas de Contabilidad}

Generalmente hablando (y estoy siendo muy genérico cuando digo lo siguiente), las reglas de contabilidad para el impuesto a la renta. conducentes a determinar la renta imponible anual de una empresa, están de acuerdo con los PCGA. La contabilidad para la renta imponible y la contabilidad para ganancias de empresas antes del impuesto a la renta, están en general de acuerdo. Habiendo dicho esto, yo señalaría que las diferencias existen aquí y allá. Una empresa puede usar un método de contabilidad para llenar su formulario de declaración del impuesto a 
la renta anual y un método diferente de medir sus ganancias para el caso de reporte al gerente y para preparar sus estados de cuentas financieros destinados a personas que no pertenecen a la empresa.

\section{Haciendo cumplir los reglamentos de contabilidad}

Como lo mencioné en la sección precedente, cuando se preparan los estados de cuentas linancicros una empresa debe de seguir los Principios de Contabilidad Generalmente Aceptados (PCGA). que son las reglas fundamentales y autoritativas para medir la ganancia y para poner valores a los activos y a los pasivos. Toda persona que lee un reporte financiero está autorizada a asumir que en este reporte se han seguido los PCGA.

La idea básica detrás de los PCGA es medir la ganancia y valorizar los activos y pasivos consistentemente de empresa a empresa. establecer uniformidad a gran escala de los métodos de contabilidad para todas las empresas. La idea es asegurarse de que todos los contadores están "cantando el mismo canto y en el mismo tono", por así decirlo. También. el propósito es establecer métodos realistas y objetivos para medir la ganancia y poner valores a los activos y a los pasivos. Los organismos autorizados escriben las canciones que los contadores tienen que cantar.

Los PCGA también incluyen requisitos mínimos para el "develado", lo cual se refiere a cómo se clasifica y presenta la información en los estados de cuentas financieros y los tipos de información que deben ser agregados a los estados de cuentas financieros en forma de anotaciones. Estos develados son requeridos además para los tres estados de cuentas financieros primarios de una empresa (el estado de cuenta de la renta, la hoja de balance y el estado de cuenta del flujo de caja).

El libro de normas de los PCGA es grande. tiene más de "mil páginas". Estas normas se han desplegado por muchas décadas, algunas reglas han permanecido igual por muchos años, algunas han sido diferidas y modificadas de vez en cuando, y nuevas reglas han sido agregadas. Recientemente, han estado saliendo pronunciamientos "oficiales" a razón de cuatro o cinco al año. que provienen de las Oficina de Normas de Contabilidad Financiera y otros organismos que generan los PCGA.

Las reglas de la contabilidad pueden tener grandes cambios. Considere que recientemente los métodos de contabilidad para los beneficios después de la jubilación pagados por las empresas AFP a sus afiliados jubilados fueron cambiados. Este nuevo modelo de contabilidad resultó en cargos de millones de nuevos soles. hechos por única vez a muchas grandes corporaciones (Estado) por los años de gastos que no habían registrado antes. Usted también puede encontrar interesante que el estado de cuenta del flujo de caja fue hecho obligatorio en 1995.

¿. Cómo sabe si las empresas siguen de verdad las reglas fielmente?. Yo creo que se resume a dos factores: Primero, es la competencia y los modelos éticos de los contadores que preparan los reportes financieros. No existe sustituto para la experiencia e integridad de los contadores que preparan los reportes financieros. Pero a menudo los contadores se encuentran bajo intensa presión de los ejecutivos de más alto nivel para los que ellos trabajan en las empresas. 
Lo cual conduce al segundo factor. que las empresas tengan sus estados de cuentas financieros auditados por contadores colegiados independientes. En efecto, se requiere que las empresas tengan auditorías anuales. realizadas por contadores colegiados externos; muchas empresas privadas emplean contadores colegiados para hacer una auditoría anual, aunque no sea obligatorio legalmente. 